\title{
Size of wildfires in the Euro-Mediterranean region: observations and theoretical analysis
}

\author{
C. Hernandez ${ }^{1}$, P. Drobinski ${ }^{1}$, S. Turquety ${ }^{1}$, and J.-L. Dupuy ${ }^{2}$ \\ ${ }^{1}$ Institut Pierre Simon Laplace/Laboraratoire de Météorologie Dynamique, CNRS/Ecole Polytechnique/Université Pierre et \\ Marie Curie, Palaiseau, France \\ ${ }^{2}$ Unité de Recherches Ecologie des Forêts Méditerranéennes, INRA, Avignon, France \\ Correspondence to: C. Hernandez (charles.hernandez@lmd.polytechnique.fr)
}

Received: 09 January 2015 - Published in Nat. Hazards Earth Syst. Sci. Discuss.: 09 February 2015

Revised: 25 May 2015 - Accepted: 08 June 2015 - Published: 23 June 2015

\begin{abstract}
MODIS (Moderate Resolution Imaging Spectroradiometer) satellite observations of fire size and ERA-Interim meteorological reanalysis are used to derive a relationship between burnt area and wind speed over the Mediterranean region and Eastern Europe. The largest wildfire size does not show a strong response with respect to wind speed in Eastern Europe. In the Mediterranean, as intuitively expected, the burnt area associated with the largest wildfires is an increasing function of wind speed for moderate temperature anomalies. In situations of severe heatwaves, the relationship between burnt area and wind speed displays a bimodal shape. Burnt areas are large for low $10 \mathrm{~m}$ wind speed (lower than $2 \mathrm{~m} \mathrm{~s}^{-1}$ ), decrease for moderate wind speed values (lower than $5 \mathrm{~m} \mathrm{~s}^{-1}$ and larger than $2 \mathrm{~m} \mathrm{~s}^{-1}$ ) and increase again for high wind speed (higher than $5 \mathrm{~m} \mathrm{~s}^{-1}$ ). To explain such behavior we use a stochastic model of fire propagation, known as a probabilistic cellular automata. This model uses a probabilistic local rule to derive the total burnt area. The observed relationship between burnt area and wind speed can be interpreted in terms of percolation threshold above which the propagation in the model is infinite, which mainly depends on local terrain slope and vegetation state (type, density, fuel moisture). In Eastern Europe, the percolation threshold is never exceeded for observed wind speeds. In the Mediterranean Basin we see two behaviors. During moderately hot weather, the percolation threshold is passed when the wind grows strong. On the other hand, in situations of severe Mediterranean heatwaves, moderate wind speed values impair the propagation of the wildfire against the wind and do not sufficiently accelerate the forward propagation to allow a growth of wildfire size.
\end{abstract}

\section{Introduction}

Large wildfires can have a significant impact on natural, social and economic systems. If most fires are extinguished in the initial stages and remain small, the largest forest fire events represent most of the area burnt and can have catastrophic consequences. The Mediterranean basin is also the major European region where wildfires occur, with about $90 \%$ of the European burnt area (Chuvieco, 2009). Vegetation fires burnt an average 200000 ha annually in the Mediterranean Basin between 1960 and 1970; the figure attained over 400000 ha in the 1970 s and over 600000 ha in the 1980s (Le Houérou, 1987). Indeed, it increased tenfold between the 1873-1972 time period and the following three decades (Pausas and Fernandez-Muñoz, 2012). Between 1980 and 2003, $57 \%$ of the total burnt area and $38 \%$ of all ignited fires in Europe burnt in Portugal (EFFIS, 2003; San-Miguel-Ayanz et al., 2013; Ganteaume et al., 2013). The main cause of this trend of Mediterranean wildfires has been attributed to rural depopulation, inducing an increase in fuel amount and causing a change in fire regime from fuel-limited to drought-driven (Pausas and FernandezMuñoz, 2011). Large wildfire occurrence is also affected by special weather conditions which do not affect most other fires (Alvarado et al., 2008).

Wildfire propagation is impacted by various conditions such as fuel moisture and load, human activities and shortto long-term weather (Flannigan et al., 2009). Wind speed is one of the main factors regarding the weather dependency, as it drives the rate of spread and direction of propagation (Rothermel, 1972). Fuel moisture is also an important factor 
for the propagation of wildfires (Sharples, 2008). It depends on short (i.e. 1-hour timescale) to medium (i.e. seasonal timescale) variability of temperature, precipitations and relative humidity.

The relationships between weather, vegetation and wildfire-burnt area have been investigated in several works. Flannigan and Wotton (2001) link seasonal burnt area with weather at various time and spatial scales (several years to a few days; global to local) and show that warm, dry and windy days are correlated with higher burnt area, and that certain synoptic conditions such as the breakdown of an upper blocking ridge leads to particularly favorable conditions for wildfires. Flannigan and Harrington (1988) show the weather dependency of monthly burnt area with long sequences of dry and low precipitations days. These relationships have been extrapolated for forecasting future wildfire severity in a changing climate. The review by Flannigan et al. (2009) indicates with high confidence that climate change should lead a positive trend of burnt area. This is already measurable in the western US, as suggested by Westerling et al. (2006) and Running (2006). Increase in the fire season duration, higher summer temperature, earlier melting of snowpacks and expansion of the areas susceptible to wildfires to elevated forests combine their effects, leading in this region to higher seasonal burnt area since the mid 1980s.

Fire occurrences in the Mediterranean region are driven by human (e.g. land use) and environmental (e.g. weather and topography) factors (Ganteaume et al., 2013). The synoptic weather conditions favorable to Mediterranean wildfires are either blocking (Pereira et al., 2005) or trough (Levin and Saaroni, 1999). Temperature anomalies (Bedia et al., 2014) and summer droughts (Dimitrakopoulos et al., 2011) are also critical in explaining fire occurrences in the Mediterranean Basin. On longer timescales, the aridity level is also linked with large fire occurrences (Pausas and Paula, 2012). In Greece, Koutsias et al. (2013) found a positive correlation between 2 years lagged precipitations and burnt area. This climatic driving of burnt area will be impacted by climate and land cover changes. In particular the combination of several factors including rural depopulation and increased fire frequency due to rising temperatures in southern Europe could lead to a general change in the dominant vegetation species, with a predominance of shrublands over forested areas (Moreira et al., 2011). Other studies suggest that the change in fire regime will be different depending on whether the climate shifts towards warmer-drier (less fire activity) or warmerwetter (more fire activity) conditions in the Mediterranean Basin (Batllori et al., 2013), a question which remains unanswered.

In order to further these studies, our aim is to analyze the role of short- and mid-term weather on the burnt area in the Euro-Mediterranean region, characterized by a variety of land uses (natural forests, chaparral, agricultural fields), high exposure to heatwaves (Stéfanon et al., 2012) and a high wildfire activity. Wildfires in the Mediterranean region tend to be generally caused by accidents (Silva et al., 2010; Ganteaume et al., 2013) and in eastern Europe they are mostly linked to agricultural practices (Turquety et al., 2014). Here we will not study the causes of wildfire activity but the dependency between fire size and weather, in particular wind speed and temperature anomaly. This study continues the work of Cardil et al. (2014) on the link between temperature anomalies and wildfire size and the work of Pausas and Paula (2012) and Loepfe et al. (2014) on threshold effects on wildfire propagation (e.g. threshold on aridity level) by analyzing the influence of wind speed on burnt area. To complete our goal, we need a comprehensive database of recent wildfires that occurred in this region and the accompanying weather. The availability of remote sensing observations since the 1990s allows the analysis of large, consistent data sets on wildfire activity. In this study we use the MODIS-retrieved burnt area with the ERA-Interim meteorology to analyze the dependency of fire size with wind speed and temperature anomaly. In order to better understand the variations seen in the observations we need to use a model of fire spread. In this study we choose to focus on probabilistic cellular automata (PCA). Our study relies on the following data-driven observation: under certain circumstances wildfires tend to decrease in size with moderate wind speed. A possible cause of such behavior is sought by simulating with a PCA model the fire propagation with varying wind speeds. The robustness of the study with respect to the model parameters will be tested.

After the introduction in Sect. 1, Sect. 2 details the data source, the methodology of data processing and analyzes the wildfire burnt area with respect to wind speed and temperature. Section 3 describes the wildfire model used for the theoretical analysis of the dependence of burnt area with respect to wind speed. Section 4 provides an in-depth discussion of the processes explaining the relationship between the wildfire burnt area and the weather. Section 5 concludes the study.

\section{Wildfire burnt area observations: methodology and analysis}

\subsection{Data source}

Meteorological data are the $10 \mathrm{~m}$ wind speed and $2 \mathrm{~m}$ air temperature from the ERA-Interim reanalysis of the European Center for Mean-Range Weather Forecast (ECMWF), which provides data from 1979 onwards, and continues in real time (Simmons et al., 2006; Dee et al., 2011). The data are available every $6 \mathrm{~h}$ at a $0.75^{\circ} \times 0.75^{\circ}$ longitude/latitude resolution. In the present study, only the 12:00 UTC data are used.

Wildfire burnt areas result from the fire detection based on the observations from the MODIS instrument (Moderate Resolution Imaging Spectroradiometer) on board of Aqua and Terra polar heliosynchronous orbiting satellites. Daily burnt areas are identified when land cover, and thus surface 
reflectance, changes drastically and rapidly due to the wildfires (Roy et al., 2008). In the present study, the modified version of the MCD64 burnt area product is used over a period of 10 years (2003-2012) and provides the daily burnt area on a $500 \mathrm{~m}$ horizontal grid (Giglio et al., 2010). Only the fraction of each grid cell covered by vegetation is allowed to burn, following Turquety et al. (2014). The uncertainty can be high for wildfires smaller than $25 \mathrm{ha}$, a size that corresponds to one pixel of the MCD64 product. There is no lower bound for the size of the detected wildfires in the data set, since the fraction of vegetation inside a given pixel can be small. We also use the European Forest Fire Information System (EFFIS) data set in our study (European Commission, 2010; San-Miguel-Ayanz et al., 2012). It is provided by the Joint Research Center of the European Commission, and is built using MODIS images at $250 \mathrm{~m}$ horizontal resolution. A first step of automated classification is used to isolate fire events and a post-processing using human visualization of the burnt scar is performed. A crossanalysis using the active fire MODIS product, fire event news collected in the EFFIS News module as well as land-cover data sets is finally done to ensure a low number of misclassifications (http://forest.jrc.ec.europa.eu/effis/). The system records burnt areas of approximately 40 ha and larger (Sedano et al., 2013). Fires under this threshold exist in this data set, with a higher associated uncertainty. Data are provided for the 2006-2012 time period on the Mediterranean Basin.

Because the drivers of the wildfires can change over the course of the year, and because the largest wildfires occur in summer, we only consider wildfires detected in July and August.

\subsection{Data processing}

A regridded version at $10 \mathrm{~km}$ resolution of the modified MCD64 product is used. A 3-D (latitude, longitude and time) connected component algorithm is applied to extract distinct fire events (Haralick and Shapiro, 1992). The principal strength of this method is that it allows the detection of wildfires extending over more than 10000 ha, since adjacent burning cells are connected. This is of particular importance since only large wildfires are investigated in the present study. Its main weakness is that it does not take into account cloud cover impairment of remote sensing. Another problem is that two independent fire events occurring close to one another (less than $20 \mathrm{~km}$ of distance and less than a day between the end of the first event and the beginning of the second) are considered the same with this method. The processing of the EFFIS data set is simpler. It provides the date coordinates of the shape of each wildfire. We take as location the centroid of this shape.

To relate the ERA-Interim meteorological data with the fire products, the ERA-Interim data are extracted at the grid point closest to the wildfire. The ERA-Interim reanal-

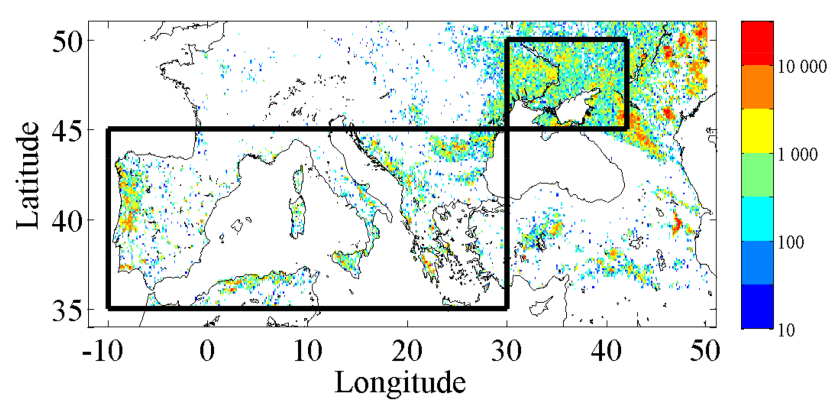

Figure 1. 10-years cumulated burnt area (in ha) for each regridded fire product grid cell over the Euro-Mediterranean region (in colors). The Mediterranean domain (MED) and central eastern Europe domain (EAST) are identified by black boxes.

ysis is the only homogenized gridded data set at the EuroMediterranean regional scale available with wind speed information. It is relevant to provide the large-scale environment in the vicinity of the wildfire. Wind speed data at finer resolution would probably add value to refine the relationship between wind speed and wildfire, especially in terms of wind speed range (which is probably underestimated with the ERA-Interim data set).

\subsection{Data analysis}

Figure 1 shows the cumulated wildfire burnt areas as retrieved by MODIS over the 10-year period (2003-2012). If a grid point has burnt entirely during this 10 -year period, the cumulated burnt area is 10000 ha. We see that the most wildfire-prone regions are the Mediterranean Basin and central Eastern Europe. In the following, we differentiate the two regions and the Mediterranean Basin will be referred to as MED, whereas central eastern Europe will be referred to as EAST.

In this study large wildfires are considered as extreme fires and are identified when the value of the burnt area exceeds the upper 95th quantile of the local probability density function. These wildfires cause the majority of the destruction (more than $50 \%$ of the burnt area in the EFFIS and MODIS data sets). Figure 2 shows the dependence of the 95th quantile of burnt area to the $10 \mathrm{~m}$ wind speed for an anomaly of the $2 \mathrm{~m}$ air temperature with respect to the climatology (19792012) $\left(\Delta T_{2}\right)$ smaller than $3{ }^{\circ} \mathrm{C}$ and exceeding $3^{\circ} \mathrm{C}$ (heatwave). In Fig. 2, the wildfire-wind speed pairs are placed in 7 bins according to wind speed, with an equal number of samples in each bin and therefore varying wind speed ranges for each bin. These 7 bins constitute separate sets for which we compute the value of the 95th quantile of fire size and its corresponding $70 \%$ confidence interval by bootstrapping this statistic 1000 times. For consistency we also show the median (blue) and 75th (green) quantiles of fire size. It can be noted that they do not show strong responses to the chosen meteorological parameters. We will therefore focus on 
the largest wildfires only. Large temperature anomalies are generally associated with an anticyclonic anomaly, persisting heat waves (Black et al., 2004; Cassou et al., 2005; Barriopedro et al., 2011; Stéfanon et al., 2012) and a larger burnt area (Pereira et al., 2005). In the EAST domain, extreme wildfire size is nearly independent of the wind speed for $\Delta T_{2}<3 \mathrm{~K}$ and slightly increases with wind speed for $\Delta T_{2}>3 \mathrm{~K}$. In the MED domain, a totally different behavior is found. For $\Delta T_{2}<3 \mathrm{~K}$, extreme wildfire burnt areas increase with wind speed, similarly to what is found in the EAST domain for larger temperature anomalies. For $\Delta T_{2}>3 \mathrm{~K}$, a bimodal dependence is found. A large number of wildfires occur for low wind speed (i.e. weaker than $2 \mathrm{~m} \mathrm{~s}^{-1}$ ) and for high wind speed (i.e. stronger than $4 \mathrm{~m} \mathrm{~s}^{-1}$ ). The bimodal dependence of wildfire burnt areas to wind speed in the MED region for situations associated with heatwaves is counter-intuitive since the rate of spread is a growing function of wind speed (Rothermel, 1972). To understand these observations, a probabilistic cellular automaton model is adapted in Sect. 3 to include the impact of wind speed on fire propagation and derive the burnt area.

\section{Wildfire burnt area simulations: sensitivity to wind speed}

\subsection{Probabilistic cellular automaton}

Several types of fire models exist. One of them is the probabilistic cellular automaton (PCA), which relies on a stochastic fire propagation set by a probability of propagation which depends on wind speed and direction, terrain slope and vegetation state. Despite its simplicity, such a model presents enough similarities with fire propagation dynamics to ensure accurate verification against observations and to allow in-depth analysis of fire propagation dynamics for a moderate computational cost (Berjak and Hearne, 2002; Trunfio, 2004; Hernández Encinas et al., 2007a, b; Alexandridis et al., 2008). Unlike coupled fire-atmosphere models such as FIRETEC (Linn et al., 2002), the PCA model does not rely on physical processes that govern the fire behavior. However, its simple implementation allows easier theoretical analysis.

The PCA implements a grid of cells that can be in a finite number of states and a local rule that determines the probability of transition between states at each time step. In our case we use the most elementary form of PCA for fire simulation, taking into account only the effect of wind speed on fire spread. The grid is a regular square lattice of cells and we choose 3 different states for the cells.

- State 0 corresponds to an unburnt cell.

- State 1 corresponds to the situation of a burning cell. The cells in this state can propagate the fire.

- State 2 corresponds to the situation of an already burnt cell.
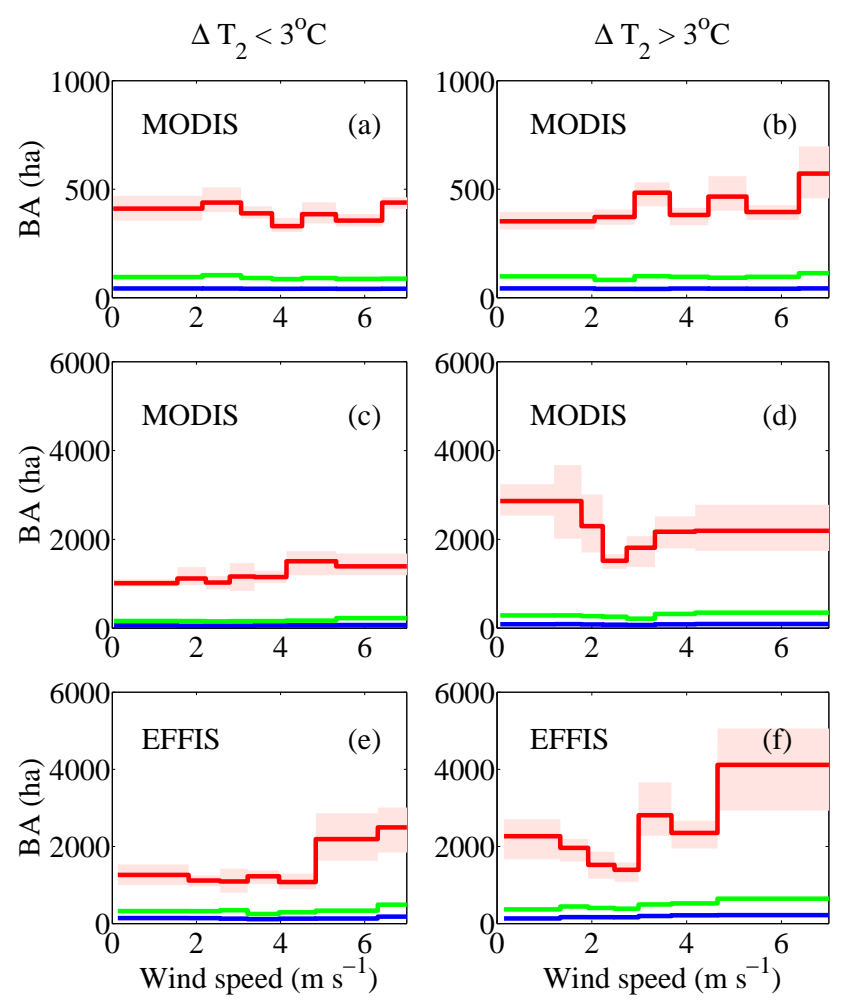

Figure 2. Wildfire burnt areas (BA) (i.e. 50th (blue), 75th (green) and 95th (red) quantiles of the local probability density function) as a function of $10 \mathrm{~m}$ wind speed for the EAST (top row panels) and MED domains (middle and bottom row panels) for $\Delta T_{2}<3{ }^{\circ} \mathrm{C}$ (left column panels) and $\Delta T_{2}>3{ }^{\circ} \mathrm{C}$ (right column panels). The pink shaded area shows the $70 \%$ confidence intervals for the 95 th quantile. For the MED region we display the quantiles derived with the MODIS (middle row panels) and EFFIS (bottom row panels) data sets.

The probability that a cell in state 1 can spread the fire to its neighbors is defined by Eq. (1):

$p=\min \left(\gamma p_{0} f(V, \theta), 1\right)$,

with $V$ the surface wind speed, $\theta$ the angle between the direction of propagation and the wind and $\gamma$ a corrective factor for diagonal spread. The quantity $p_{0}$ is a constant and is the spreading probability in absence of wind. The function $f$ of wind is defined in Alexandridis et al. (2008) as

$f(V, \theta)=\exp \left[V\left(c_{1}+c_{2} \cos \theta-1\right)\right]$.

The quantities $c_{1}$ and $c_{2}$ are empirical factors set respectively to 0.045 and $0.131 \mathrm{~s} \mathrm{~m}^{-1}$ (Alexandridis et al., 2008). The shape of $f(V, \theta)$ is shown in Fig. 3 for various values of wind speed. Function $f$ is isotropic with zero wind and gradually expands in the direction of the wind. The corrective factor $\gamma$ is set at $\frac{1}{\sqrt{2}}$ such as the fire propagation is isotropic in absence of wind speed. Without such a correcting factor the fire would take a square form in the absence of wind. 


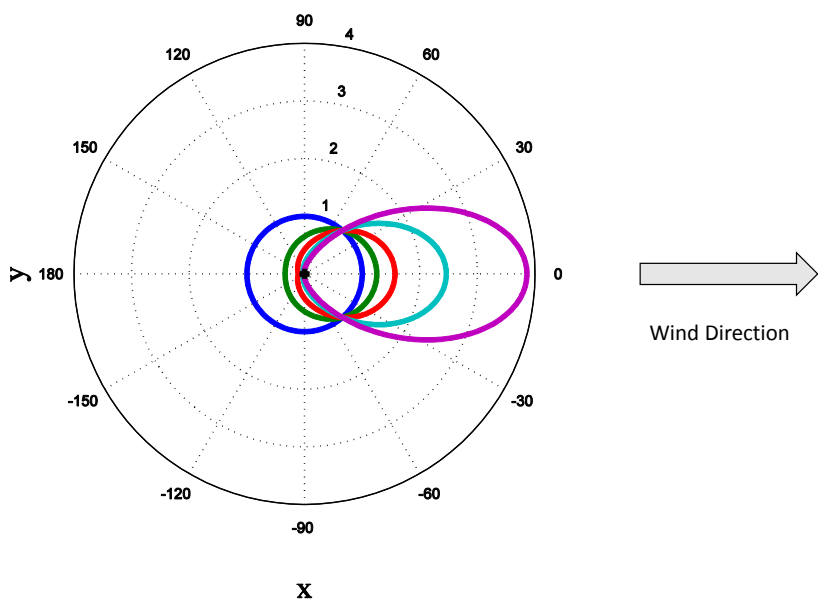

Figure 3. Polar plot of the function $f(V, \theta)$ for values of wind speed $V$ equal to 0 (blue), 5 (green), 10 (red), 20 (cyan) and $30 \mathrm{~m} \mathrm{~s}^{-1}$ (purple). The $f$ function expresses the dependency of the local fire propagation probability to wind speed and angle of propagation. Here the wind follows the $x$ axis direction.

Figure 4 shows the fraction of burnt cells $y_{2}^{\text {final }}$ - with $y_{i}$ the fraction of cells in state $i$ in the PCA grid - as a function of $p_{0}$ when the fire is extinct in a grid constituted of $101 \times 101$ cells. The quantity $y_{2}^{\text {final }}$ is computed from a Monte Carlo simulation. Figure 4 displays a transition at $p_{0} \sim 0.275$ between a mode where very few cells are burnt $\left(y_{2}^{\text {final }} \sim 0\right)$ and another one where the fire begins to spread on a large portion of the grid.

\subsection{Percolation threshold analysis}

Above a certain value of the propagation probability $p$ the fire can thus propagate indefinitely in the PCA. The critical value $p_{0}^{\text {crit }}$ of the $p_{0}$ constant is shown in Fig. 4 for the zero wind case. This phenomenon is called percolation and can be analyzed theoretically. Pak and Hayakawa (2011) studied the percolation threshold for an elementary form of PCA, with no diagonal propagation or wind speed effect. They state with the help of a mean-field approximation that the fraction of cells in states 1 and 2 are governed by Eqs. (3)-(5).

$\frac{\mathrm{d} y_{1}}{\mathrm{~d} t}=4 p y_{1} y_{0}-a_{12} y_{1}$

$\frac{\mathrm{d} y_{2}}{\mathrm{~d} t}=a_{12} y_{1}$

$y_{0}+y_{1}+y_{2}=1$,

with $y_{i}$ the fraction of cells in state $i$ in the PCA grid, $p$ the probability of fire spread and $a_{12}$ the probability that a cell in state 1 at time $t$ goes to state 2 at time $t+1$. In our case, the quantity $a_{12}$ is set to 1 . In the study, we adapt the PCA model to account for wind speed effect and diagonal propagation. Equation (3) is thus modified as follows:

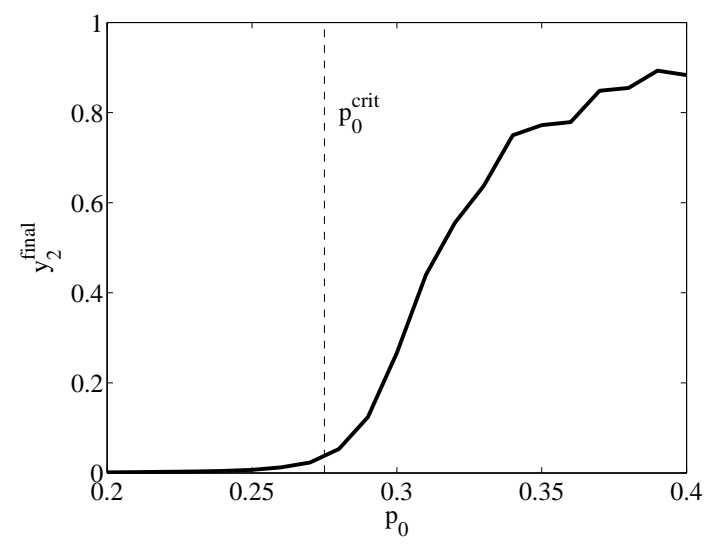

Figure 4. Evolution of the fraction of burnt cells $y_{2}^{\text {final }}-$ with $y_{2}$ the fraction of cells in state "burnt" in the PCA grid - as a function of $p_{0}$ when the fire is extinct in a grid constituted of $101 \times 101$ cells. The simulation is performed in the absence of wind. The quantity $p_{0}$ is the constant part of the local fire propagation probability, which can be seen as a proxy of fuel density, type and moisture. The quantity $p_{0}^{\text {crit }}$ is the percolation (infinite propagation in the PCA) threshold.

$\frac{\mathrm{d} y_{1}}{\mathrm{~d} t}=C(V) p_{0} y_{1} y_{0}-y_{1}$,

with $C(V)$ a weighting coefficient which allows to account for fire spreading in various directions as a function of the wind speed. It writes:

$$
\begin{aligned}
C(V) & =\exp \left(V c_{1}\right)+2 \exp \left[V\left(c_{1}-c_{2}\right)\right]+\exp \left[V\left(c_{1}-2 c_{2}\right)\right] \\
& +2 \gamma \exp \left\{V\left[c_{1}+c_{2}\left(\frac{\sqrt{2}}{2}-1\right)\right]\right\} \\
& +2 \gamma \exp \left\{V\left[c_{1}-c_{2}\left(\frac{\sqrt{2}}{2}+1\right)\right]\right\}
\end{aligned}
$$

The first term of the sum on the right-hand-side of Eq. (7) corresponds to a propagation along the wind direction, the second term to a propagation across the wind direction and the third to a propagation against the wind. The other terms correspond to diagonal propagation $(\sqrt{2} / 2$ corresponds to $\cos (\pi / 4))$. The details of the derivation of Eq. (7) is provided in the Appendix. Equation (7) can be simplified:

$$
\begin{aligned}
C(V) & =\exp \left(V c_{1}\right) \times\left\{\left[1+\exp \left(-V c_{2}\right)\right]^{2}\right. \\
& +\sqrt{2}\left(\exp \left[V c_{2}\left(\frac{\sqrt{2}}{2}-1\right)\right]\right. \\
& \left.\left.+\exp \left[-V c_{2}\left(\frac{\sqrt{2}}{2}+1\right)\right]\right)\right\} .
\end{aligned}
$$

Following the methodology of Pak and Hayakawa (2011), we derive a relationship between $p_{0}^{\text {crit }}$ and the wind speeddependent coefficient $C(V)$ : 

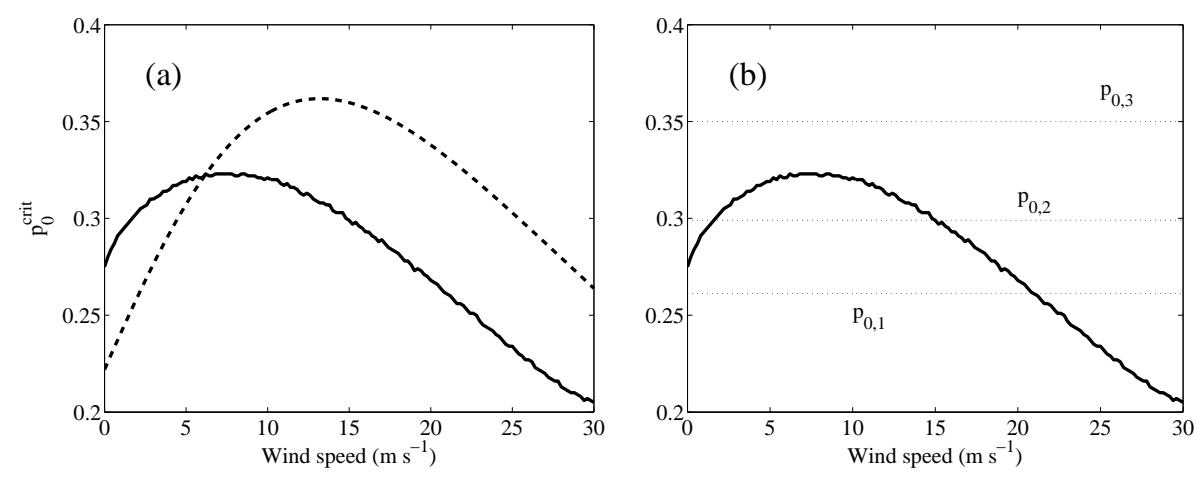

Figure 5. $p_{0}^{\text {crit }}$ the percolation (infinite propagation in the PCA) threshold as a function of wind. Dashed curve is the theoretical value found using mean-field approximation and the full curve is the numerically derived value. Dotted lines $\left(p_{0,1}\right),\left(p_{0,2}\right)$ and $\left(p_{0,3}\right)$ correspond to the curves plotted in Fig. 6.

$p_{0}^{\text {crit }}=\frac{1.51552}{C(V)}$

The value of the numerator comes from site percolation theory. For further insight, Pak and Hayakawa (2011) give an introduction to bond and site percolation theory. This equation is plotted in Fig. 5, along with the numerically derived $p_{0}^{\text {crit. }}$. To compute this quantity numerically we consider that percolation occurs when a fire initiated in the middle of our $101 \times 101$ PCA grid reaches the edges of the domain. The $p_{0}$ value increases from 0.2 with 0.001 increments. The critical value $p_{0}=p_{0}^{\text {crit }}$ is set when more than $90 \%$ of a 300 simulation ensemble percolate. We can see that both the theoretical and computed values $p_{0}^{\text {crit }}$ increase with wind speed for low wind values, reach a maximum and then decrease with wind speed. The difference between the theoretical and computed

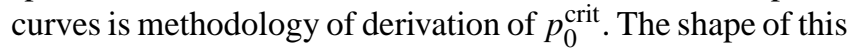
curve will be essential in the analysis of our observations in Sect. 2. In the following, we refer to $p_{0,0}^{\text {crit }}$ as the value in the absence of wind and $p_{0, \max }^{\text {crit }}$ as the maximum value reached by $p_{0}^{\text {crit }}$.

\section{Discussion}

The PCA gives us a theoretical framework to understand the results of Fig. 2. The mean fire size of the biggest wildfires (above the 95th quantile) is a growing function of wind speed in most cases, except in the Mediterranean Basin for large temperature anomalies. It is also dependent on the slope of the local topography but this has no consequence on the observed behavior of the burnt area. A proposed expression of $p_{0}$ is described in Alexandridis et al. (2008):

$p_{0}=p_{\mathrm{h}}\left(1+p_{\text {den }}\right)\left(1+p_{\text {veg }}\right) p_{\mathrm{s}}\left(\theta_{\mathrm{s}}\right)$,

where $p_{\mathrm{h}}$ is a constant used for homogeneous fuel beds, $p_{\mathrm{den}}$ and $p_{\text {veg }}$ are factors depending on vegetation density and

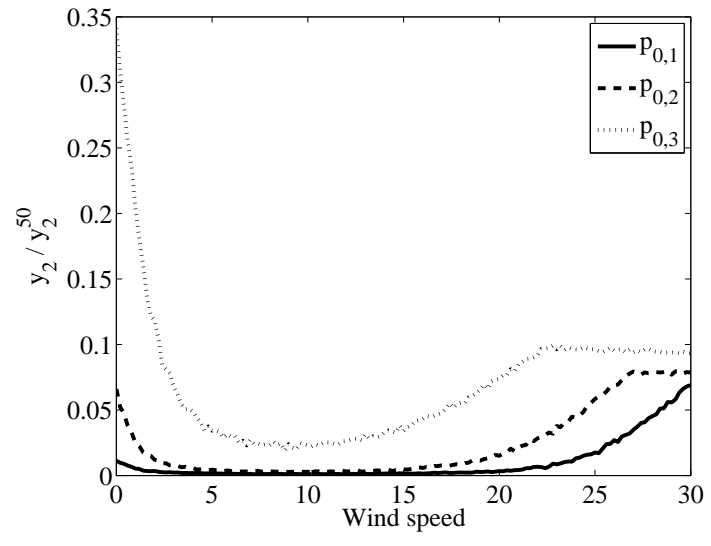

Figure 6. Fraction of burnt cells $y_{2} / y_{2}^{50}$ (normalized to its value after 50 time steps in the absence of wind speed and for $p=1$ ) as a function of wind speed for $p_{0}$ values set at $p_{0,1}=0.26$ (solid line), $p_{0,2}=0.3$ (dashed line) and $p_{0,3}=0.35$ (dotted line) in Fig. 5 .

type, respectively. The quantity $\theta_{\mathrm{s}}$ is the local slope in degrees and the expression of $p_{\mathrm{s}}\left(\theta_{\mathrm{s}}\right)$ is given by

$p_{\mathrm{s}}\left(\theta_{\mathrm{s}}\right)=\exp \left(a \theta_{\mathrm{s}}\right)$.

This formulation is very simple and other factors such as fuel moisture could be taken into account for more realistic simulations. We do not consider the effect of slope in this study. It may be a differentiating factor between EAST and MED, which could lead to quantitative differences between fire sizes in the two regions but for a given region the slope value is the same whatever the wind speed, vegetation state or temperature and soil moisture anomaly. The main cause of such behavioral differences is the value of $p_{0}$ relative to $p_{0}^{\text {crit }}$. The final burnt area can vary drastically because of percolation as seen in Fig. 4. Figure 6 displays the fraction of burnt cells (normalized to its value after 50 time steps in the absence of wind speed and for $p=1$, see Fig. 6) as a function of wind speed for three different values of $p_{0}$. Three $p_{0}$ values are chosen in the three different domains: $p_{0,1}$ set 
at 0.26 , below the 0 wind percolation threshold, $p_{0,2}=0.3$ between $p_{0,0}^{\text {crit }}$ and $p_{0, \max }^{\text {crit }}$ and $p_{0,3}=0.35$ above the maximum of the percolation threshold (Figs. 5 and 6). The saturation for strong winds visible is due to the fact that $p=1$ in the direction of the wind so has always the same shape after 50 time steps and the fraction of burnt cells saturates. For $p_{0}$ values smaller than $p_{0,0}^{\text {crit }}$, percolation is only possible for high winds so the burnt area increases with wind speed similarly to what is observed over the EAST domain and over the MED domain for low temperature anomaly $\left(\Delta T_{2}<3{ }^{\circ} \mathrm{C}\right)$. For intermediate $p_{0}$ values ranging between $p_{0,0}^{\text {crit }}$ and $p_{0 \text {, max }}^{\text {crit }}$ large burnt area are simulated for low wind values (smaller than about $5 \mathrm{~m} \mathrm{~s}^{-1}$ ) and high wind speed values (higher than about $15 \mathrm{~m} \mathrm{~s}^{-1}$ ) (Fig. 6). Conversely, smaller burnt areas are simulated for intermediate wind ranging between 5 and $15 \mathrm{~m} \mathrm{~s}^{-1}$ (Fig. 6). For $p_{0}$ values larger than $p_{0, \max }^{\text {crit }}$, similar qualitative results are obtained with larger burnt areas.

We can therefore analyze Fig. 2 as if each subfigure corresponds to a different value of $p_{0}$. The value of $p_{0}$ corresponding to the EAST domain and MED domain for low temperature anomaly should be lower than $p_{0,0}^{\text {crit }}$, so that the burnt area increases with wind speed. The rate of burnt area increase with respect to wind speed is a function of the departure of $p_{0}$ from $p_{0,0}^{\text {crit }}$. Over the EAST domain, the value of $p_{0}$ is expected to be further below $p_{0,0}^{\text {crit }}$ than over the MED domain. It may also explain why a change in propagation regime is observed over the MED domain when shifting from low to high temperature anomalies. Indeed, for large temperature anomalies corresponding to severe heatwaves $\left(\Delta T_{2}>3{ }^{\circ} \mathrm{C}\right)$ over the MED domain, a value of $p_{0}$ exceeding $p_{0,0}^{\text {crit }}$ is expected. A simple way to understand such behavior is to consider the probability of extinction of a fire occupying one cell. Let $p$ be the spread probability. The cell has eight neighbors on a square grid. In the absence of wind, the extinction probability is $(1-p)^{8}$. When wind blows, the fire spreads in the direction of the wind and diagonally. The probability of extinction becomes $(1-p)^{3}$. Let us consider very weak wind speed values for which isotropic spreading can be assumed and $p$ increases with wind speed. Then the extinction probability $(1-p)^{8}$ drops very quickly. When isotropic spreading does not stand anymore, then the probability of extinction transitions to $(1-p)^{3}$ and increases as 3 is a lower exponent than for the isotropic spreading. With increasing wind speed, the probability of extinction decreases again. So instead of enhancing wildfire propagation, moderate winds produce smaller wildfires by cutting off the propagation against the wind. Such analysis explains the two modes observed in the MODIS and EFFIS data over the MED domain.

The function of wind $f(V, \theta)$ in the calculation of $p$ is critical in the explanation of the observed behavior (see Eq. 9). The choice of this function by Alexandridis et al. (2008) was done empirically to match with the behavior of the rate of spread of real wildfires as a function of the wind

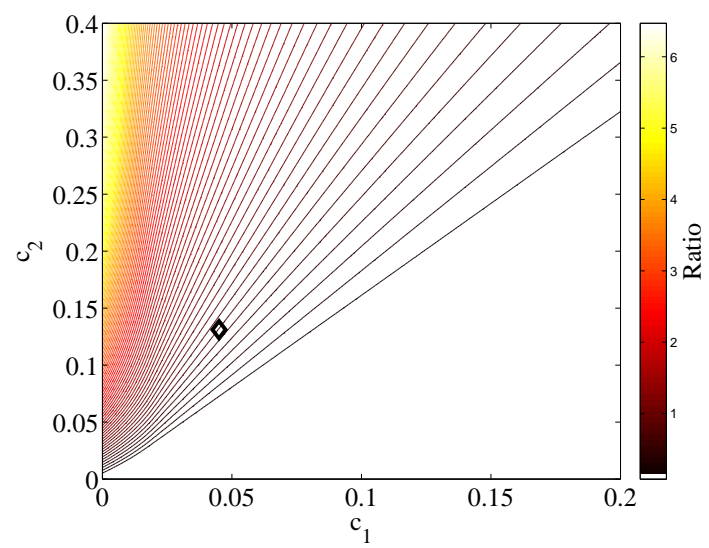

Figure 7. Ratio ( $\left.p_{0, \max }^{\text {crit }}-p_{0,0}^{\text {crit }}\right) / p_{0,0}^{\text {crit }}$ for different values of the $c_{1}$ and $c_{2}$ parameters governing the function of local fire propagation probability. $p_{0, \max }^{\text {crit }}$ is the maximum of the percolation threshold for increasing wind speeds and $p_{0,0}^{\text {crit }}$ is its value for 0 wind. The black diamond shows the $\left(c_{1}, c_{2}\right)$ pair chosen by Alexandridis et al. (2008). A strictly positive value indicates that $p_{0}^{\text {crit }}$ has a maximum value for a non-zero wind speed, which ensures that the burnt area has a local minimum for moderate values of wind speed.

and the angle between the wind direction and the direction of propagation. Its shape is coherent with real wildfire propagation but concerns can be raised (Fig. 3). The backpropagation is very small and the overall shape is non-elliptical. This last point could be due to the indirect impact of factors that alter the normally elliptical shape of small wildfires, such as the small variations in wind direction that make the wildfire slightly conical. Despite such concerns, this function has been efficient in the simulation with PCA of the 1990 burnt scar in the Spetses island in Greece (Alexandridis et al., 2008) and, thus, does fairly well for burnt scar modeling purposes.

Another concern is that the propagation speed in the direction of the wind tends to grow very quickly with the wind speed. With the expression of $f(V, \theta)$ used in this study, the propagation speed only becomes very high when the wind speed exceeds $15 \mathrm{~m} \mathrm{~s}^{-1}$ which is much too high compared to observed wildfires. Tests have been performed by using other expressions of $f(V, \theta)$, such as the elliptical form and varying the $c_{1}$ and $c_{2}$ coefficients of Eq. (2), and no qualitative difference in the behavior of $p_{0}^{\text {crit }}$ has been evidenced (not shown). In detail, the choice of $c_{1}$ and $c_{2}$ coefficients can be questioned, as it was only validated in one case study. A key issue is to know if $p_{0, \max }^{\text {crit }}$ is reached for a positive value of the wind speed, which conditions the existence of the 2 modes regime. Figure 7 shows the value of the ratio $\left(p_{0, \text { max }}^{\text {crit }}-p_{0,0}^{\text {crit }}\right) / p_{0,0}^{\text {crit }}$ as a function of $c_{1}$ and $c_{2}$ calculated from Eq. (9). For a value of $c_{2}$ larger than about $1.25 c_{1}$ this property is verified. This condition can be interpreted as the backpropagation of the wildfire being impaired in a sufficiently large angle domain by the wind. 
A possible reason for the burnt area to decrease with wind speed for moderate wind speed over the MED domain is that in order to reach a $p_{0}$ value larger than $p_{0,0}^{\text {crit }}$, higher flammability of the fuel bed or a more fire-prone environment is needed. This could be caused by the lower precipitation amounts in the MED region, which would lead to lower fuel moisture. This could also be due to different vegetation type between the EAST and MED regions.

Our analysis reveals the critical role of the percolation threshold in wildfire propagation. Here we focused our work on the dependency between burnt area and wind speed but other studies found threshold behaviors related to other explanatory variables such as the Drought Code of the Canadian Fire Weather Index (Loepfe et al., 2014) and fire season aridity (Pausas and Paula, 2012). These variables relating to fuel moisture, it could be possible to see a similar percolation threshold behavior with a PCA incorporating a propagation probability decreasing with fuel moisture.

\section{Conclusions}

The behavior of the burnt area with temperature anomaly and wind speed was analyzed with the help of MODIS observations and ERA-Interim reanalysis. In the EAST region and in MED for low temperature anomalies, the burnt area is a growing function of wind, which is rather intuitive. For large temperature anomalies in the MED region, corresponding to severe heatwaves, the burnt area behaves differently. It displays a two-mode shape with a minimum value of burnt area for medium values of the wind speed. The possible cause of such counter-intuitive behavior has been investigated theoretically by means of probabilistic cellular automata (PCA). It was found that when the wind speed is moderate, the backpropagation is impaired when the forward propagation is not sufficiently fast to compensate the loss in burnt area. Therefore if the wind is not strong enough to make the propagation along the wind direction sure enough, percolation does not happen in the PCA resulting in smaller wildfires. The percolation threshold is never reached in the EAST region. It is only exceeded for very low or high wind speeds in the MED region. Such a shift between two regimes of propagation may be caused by the favorable occurrence of severe heatwaves in the MED region.
A natural follow-up of this study would be to model the impact of fuel moisture on the propagation probability by adapting the known variations of the rate of spread of the fire with this quantity (Sharples, 2008). It could be complemented by a thorough analysis of the behavior of dead and live fuel moisture in Mediterranean ecosystems with respect to air temperature anomaly and the incorporation of such relation in the expression of the probability of fire propagation. However, fuel moisture is a quantity which is hard to assess. Live fuel moisture depends on the plant species and dead fuel moisture on the size of the fuel particle. For a more holistic approach, a more realistic fire propagation modeling framework such as FIRETEC would be needed to better identify and quantify the processes driving fire propagation. Finally, conducting observational studies on other hotspots of wildfire activity (e.g. Australia, USA) in order to see whether the 2 modes exists in other parts of the world would be of interest. 


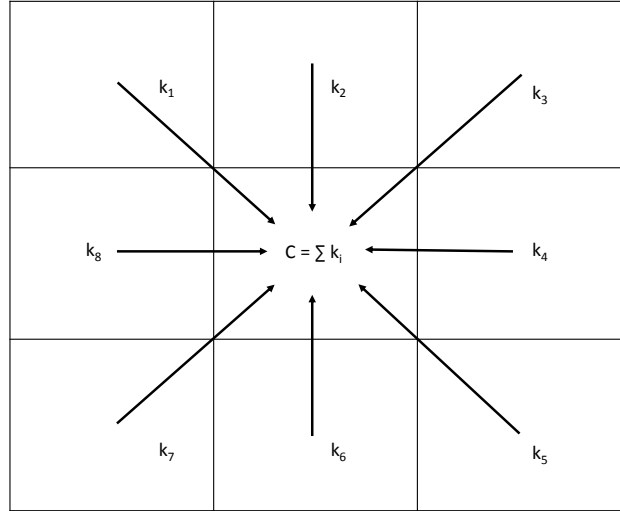

Figure A1. Schematic of the calculation of $C(V)$.

\section{Appendix A}

In this Appendix, the calculation of $C(V)$ is detailed. The quantity $C(V)$ corresponds to the sum of the probabilities that the fire propagates from a neighboring cell to the center cell (Fig. A1).

For all 8 neighbors we can write:

$p_{i}=k_{i} p_{0}$,

with $k_{i}$ being a coefficient depending on the direction of propagation. One can write

$k_{i}=\gamma_{i} \exp \left\{V\left[c_{1}+c_{2}\left(\cos \theta_{i}-1\right)\right]\right\}$,

with $\theta_{i}$ being the angle between the direction of propagation and the direction of the wind for the $i$ component and $\gamma_{i}$ being equal to $\gamma$ or 1 depending on whether the propagation direction is diagonal or not in the PCA grid. One can write: $k_{1}=k_{7}=\gamma \exp \left\{V\left[c_{1}-c_{2}(1-\sqrt{2} / 2)\right]\right\}$

$k_{2}=k_{6}=\exp \left[V\left(c_{1}-c_{2}\right)\right]$

$k_{3}=k_{5}=\gamma \exp \left\{V\left[c_{1}-c_{2}(1+\sqrt{2} / 2)\right]\right\}$

$k_{4}=\exp \left[V\left(c_{1}-2 c_{2}\right)\right]$

$k_{8}=\exp \left(V c_{1}\right)$.

The quantity $C(V)$ is the sum of the $k_{i}$ coefficients and thus writes:

$$
\begin{aligned}
C(V) & =\exp \left(V c_{1}\right)+2 \exp \left[V\left(c_{1}-c_{2}\right)\right]+\exp \left[V\left(c_{1}-2 c_{2}\right)\right] \\
& +2 \gamma \exp \left\{V\left[c_{1}+c_{2}\left(\frac{\sqrt{2}}{2}-1\right)\right]\right\} \\
& +2 \gamma \exp \left\{V\left[c_{1}-c_{2}\left(\frac{\sqrt{2}}{2}+1\right)\right]\right\}
\end{aligned}
$$

which can be simplified into:

$$
\begin{aligned}
C(V) & =\exp \left(V c_{1}\right) \times\left\{\left[1+\exp \left(-V c_{2}\right)\right]^{2}\right. \\
& +\sqrt{2}\left(\exp \left[V c_{2}\left(\frac{\sqrt{2}}{2}-1\right)\right]\right. \\
& \left.\left.+\exp \left[-V c_{2}\left(\frac{\sqrt{2}}{2}+1\right)\right]\right)\right\}
\end{aligned}
$$

using $\gamma=1 / \sqrt{2}$. 
Acknowledgements. This work contributes to the HyMeX program (HYdrological cycle in The Mediterranean EXperiment Drobinski et al., 2014) through INSU-MISTRALS support and the GEWEX hydroclimate panel of the World Climate Research Program (WCRP). Data were provided by the European Forest Fire Information System - EFFIS (http://effis.jrc.ec.europa.eu) of the European Commission Joint Research Center.

Edited by: P. Tarolli

Reviewed by: two anonymous referees

\section{References}

Alexandridis, A., Vakalis, D., Siettos, C. I., and Bafas, G. V.: A cellular automata model for forest fire spread prediction: The case of the wildfire that swept through spetses island in 1990, Appl. Math. Comput., 204, 191-201, 2008.

Alvarado, E., Sandberg, D. V., and Pickford, S. G.: Modelling large forest fires as extreme events, Northw. Sci., 72, 66-75, 2008.

Barriopedro, D., Fischer, E. M., Luterbacher, J., Trigo, R. M., and Garcia-Herrera, R.:The hot summer of 2010: redrawing the temperature record map of Europe Science, 332, 220-224, 2011.

Batllori, E., Parisien, M. A., Krawchuk, M. A., and Moritz, M. A.: Climate change-induced shifts in fire for Mediterranean ecosystems, Global Ecol. Biogeogr., 22, 1118-1129, 2013.

Bedia, J., Herrera, S., and Gutiérrez, J. M.: Assessing the predictability of fire occurrence and area burned across phytoclimatic regions in Spain, Nat. Hazards Earth Syst. Sci., 14, 53-66, doi:10.5194/nhess-14-53-2014, 2014.

Berjak, S. G. and Hearne, J. W.: An improved cellular automaton model for simulating fire in a spatially heterogeneous savanna system Ecol. Model., 148, 133-151, 2002.

Black, E., Blackburn, M., Harrison, G., Hoskins, B., and Methven, J.: 2004 Factors contributing to the summer 2003 European heatwave, Weather, 59, 218-223, 2004.

Cardil, A., Salis, M., Spano, D., Delogu, G., and Molina Terrén, D.: Large wildland fires and extreme temperatures in Sardinia (Italy) iForest-Biogeosci. Forest., 7, 162-169, 2014.

Cassou, C., Terray, L., and Phillips, A. S.: Tropical Atlantic influence on European heatwaves, J. Climate, 18, 2805-2810, 2005.

Chuvieco, E.: Earth observation of wildland fires in Mediterranean ecosystems, Springer Ed., Dordrecht, the Netherlands, 251 pp., 2009.

Dee, D., Uppala, S., Simmons, A., Berrisford, P., Poli, P., Kobayashi, S., Andrae, U., Balmaseda, M., Balsamo, G., Bauer, P., Bechtold, P., Beljaars, A. C. M., van de Berg, L., Bidlot, J., Bormann, N., Delsol, C., Dragani, R., Fuentes, M., Geer, A. J., Haimberger, L., Healy, S. B., Hersbach, H., Hólm, E. V., Isaksen, L., Kållberg, P., Köhler, M., Matricardi, M., McNally, A. P., Monge-Sanz, B. M., Morcrette, J. J., Park, B. K., Peubey, C., de Rosnay, P., Tavolato, C., Thépaut, J. N., and Vitart, F.: The erainterim reanalysis: Configuration and performance of the data assimilation system, Q. J. Roy. Meteorol. Soc., 137, 553-597, 2011.

Dimitrakopoulos, A. P., Vlahou, M., Anagnostopoulou, C. G., and Mitsopoulos, I. D.: Impact of drought on wildland fires in Greece: implications of climatic change?, Climatic Change, 109, 331-347, 2011.
Drobinski, P., Ducrocq, V., Alpert, P., Anagnostou, E., Béranger, K., Borga, M., Braud, I., Chanzy, A., Davolio, S., Delrieu, G., Estournel, C., Filali Boubrahmi, N., Font, J., Grubisic, V., Gualdi, S., Homar, V., Ivancan-Picek, B., Kottmeier, C., Kotroni, V., Lagouvardos, K., Lionello, P., Llasat, M. C., Ludwig, W., Lutoff, C., Mariotti, A., Richard, E., Romero, R., Rotunno, R., Roussot, O., Ruin, I., Somot, S., Taupier-Letage, I., Tintore, J., Uijlenhoet, R., and Wernli, H.: HyMeX, a 10-year multidisciplinary program on the Mediterranean water cycle, B. Am. Meteorol. Soc., 95, 1063-1082, 2014.

EFFIS: Forest fires in Europe - 2003 fire campaign, Joint Research Center, European Commission, available at: http:// forest.jrc.ec.europa.eu/effis/reports/annual-fire-reports/ (last access: 22 June 2015), 2003.

European Commission: Forest Fires in Europe 2009, EUR 24502 EN, Office for Official Publications of the European Communities, Luxembourg, 2010.

Flannigan, M. D. and Harrington, J.: A study of the relation of meteorological variables to monthly provincial area burned by wildfire in canada (1953-80), J. Appl. Meteorol., 27, 441-452, 1988.

Flannigan, M. D. and Wotton, B.: Climate, weather, and area burned, Forest fires, Academic Press, New York, p. 351, 2001.

Flannigan, M. D., Krawchuk, M. A., de Groot, W. J., Wotton, B. M., and Gowman, L. M.: Implications of changing climate for global wildland fire, Int. J. Wildland Fire, 18, 483-507, 2009.

Ganteaume, A., Camia, A., Jappiot, M., San-Miguel-Ayanz, J., Long-Fournel, M., and Lampin, C.: A review of the main driving factors of forest fire ignition over Europe, Environ. Manage., 51, 651-662, 2013.

Giglio, L., Randerson, J. T., van der Werf, G. R., Kasibhatla, P. S., Collatz, G. J., Morton, D. C., and DeFries, R. S.: Assessing variability and long-term trends in burned area by merging multiple satellite fire products, Biogeosciences, 7, 1171-1186, doi:10.5194/bg-7-1171-2010, 2010.

Haralick, M. and Shapiro, L. G.: Computer and Robot Vision, Addison-Wesley, 1, 28-48, 1992.

Hernández Encinas, A., Hernández Encinas, L., Hoya White, S., Martín del Rey, A., and Rodríguez Sánchez, G.: Simulation of forest fire fronts using cellular automata, Adv. Eng. Softw., 38, 372-378, 2007a.

Hernández Encinas, L., Hoya White, S., Martín del Rey, A., and Rodríguez Sánchez, G.: Modelling forest fire spread using hexagonal cellular automata, Appl. Math. Model., 31, 1213-1227, 2007b.

Koutsias, N., Xanthopoulos, G., Founda, D., Xystrakis, F., Nioti, F., Pleniou, M., Mallinis, G., and Arianoutsou, M.: On the relationships between forest fires and weather conditions in Greece from long-term national observations (1894-2010), Int. J. Wildland Fire, 22, 493-507, 2013.

Le Houérou, H. N.: Vegetation wildfires in the Mediterranean basin: evolution and trends, Ecol. Mediter., 13, 13-24, 1987.

Levin, N. and Saaroni, H.: Fire weather in Israel - synoptic climatological analysis, GeoJournal, 47, 523-538, 1999.

Linn, R., Reisner, J., Colman, J. J., and Winterkamp, J.: Studying wildfire behavior using firetec, Int. J. Wildland Fire, 11, 233246, 2002.

Loepfe, L., Rodrigo, A., and Lloret, F.: Two thresholds determine climatic control of forest fire size in Europe and northern Africa, Reg. Environ. Change, 14, 1395-1404, 2014. 
Moreira, F., Viedma, O., Arianoutsou, M., Curt, T., Koutsias, N., Rigolot, E., Barbati, A., Corona, P., Vaz, P., Xanthopoulos, G., Mouillot, F., and Bilgili, E.: Landscape-wildfire interactions in southern Europe: implications for landscape management, J. Environ. Manage., 92, 2389-2402, 2011.

Pak, S. I. and Hayakawa, T.: Forest fire modeling using cellular automata and percolation threshold analysis, in: American Control Conference (ACC), San Francisco, California, USA, 293-298, 2011.

Pausas, J. G. and Fernández-Muñoz, S.: Fire regime changes in the Western Mediterranean Basin: from fuel-limited to droughtdriven fire regime, Climatic Change, 110, 215-226, 2012.

Pausas, J. G. and Paula, S.: Fuel shapes the fire-climate relationship: evidence from Mediterranean ecosystems, Global Ecol. Biogeogr., 21, 1074-1082, 2012.

Pereira, M. G., Trigo, R. M., da Camara, C. C., Pereira, J., and Leite, S. M.: Synoptic patterns associated with large summer forest fires in Portugal, Agr. Forest Meteorol., 129, 11-25, 2005.

Rothermel, R. C.: A mathematical model for predicting fire spread in wildland fuels, Res. Pap. INT-115, US Department of Agriculture, Intermountain Forest and Range Experiment Station, Ogden, UT, p. 40, 1972.

Roy, D. P., Boschetti, L., Justice, C. O., and Ju, J.: The collection 5 MODIS burned area product - Global evaluation by comparison with the MODIS active fire product, Remote Sens. Environ., 112, 3690-3707, 2008.

Running, S. W.: Is global warming causing more, larger wildfires?, Science, 313, 927-928, 2006.

San-Miguel-Ayanz, J., Schulte, E., Schmuck, G., Camia, A., Strobl, P., Liberta, G., Giovando, C., Boca, R., Sedano, F., Kempeneers, P., McInerney, D. Withmore, C., Santos de Oliveira, S., Rodrigues, M., Durrant, T., Corti, P., Oehler, F., Vilar, L., and Amatulli, G.: Comprehensive Monitoring of Wildfires in Europe: The European Forest Fire Information System (EFFIS), Approaches to Managing Disaster - Assessing Hazards, Emergencies and Disaster Impacts, edited by: Tiefenbacher, J., InTech, Croatia, doi:10.5772/28441, 2012.
San-Miguel-Ayanz, J., Moreno, J. M., and Camia, A.: Analysis of large fires in European Mediterranean landscapes: lessons learned and perspectives, Forest Ecol. Manage., 294, 11-22, 2013.

Sedano, F., Kempeneers, P., San-Miguel-Ayanz, J., Strobl, P., and Vogt, P.: Towards a pan-European burnt scar mapping methodology based on single date medium resolution optical remote sensing data, Int. J. Appl. Earth Obs. Geoinf., 20, 52-59, 2013.

Sharples, J.: Review of formal methodologies for wind-slope correction of wildfire rate of spread, Int. J. Wildland Fire, 17, 179193, 2008.

Silva, J. S., Rego, F., Fernandes, P., and Rigolot, E.: Towards integrated fire management: outcomes of the European project Fire Paradox, European Forest Institute Research Report 23, European Forest Institute, Joensuu, Finland, 2010.

Simmons, A., Uppala, S., Dee, D., and Kobayashi, S.: ERA-interim: New ECMWF reanalysis products from 1989 onwards, ECMWF Newslett., 110, 25-35, 2006.

Stéfanon, M., D’Andrea, F., and Drobinski, P.: Heatwave classification over Europe and the Mediterranean region, Environ. Res. Lett., 7, 014023, doi:10.1088/1748-9326/7/1/014023, 2012.

Trunfio, G. A.: Predicting wildfire spreading through a hexagonal cellular automata model, in: Cellular Automata, Springer, Berlin, Heidelberg, 385-394, 2004.

Turquety, S., Menut, L., Bessagnet, B., Anav, A., Viovy, N., Maignan, F., and Wooster, M.: APIFLAME v1.0: high-resolution fire emission model and application to the Euro-Mediterranean region, Geosci. Model Dev., 7, 587-612, doi:10.5194/gmd-7-5872014, 2014.

Westerling, A. L., Hidalgo, H. G., Cayan, D. R., and Swetnam, T. W.: Warming and earlier spring increase western US forest wildfire activity, Science, 313, 940-943, 2006. 